\title{
A TRADUÇÃO COMO MEIO DA ESCRITURA LITERÁRIA A OBRA DE MOHAMMED MRABET TRADUZIDA POR PAUL BOWLES
}

\begin{abstract}
João Augusto de Medeiros Lira é ator, tradutor, professor de idiomas e literatura, especialista em literaturas de língua inglesa, mestre e doutorando em Teoria da Literatura pelo Programa de Pós-Graduação em Letras da Universidade Federal de Pernambuco (UFPE), dentro da linha de pesquisa em Literatura, Sociedade e Memória. Concluiu o mestrado em 2011 no mesmo programa de pós-graduação com a defesa da dissertação Poética da Errância ou Geografia da Perdição? - Paul Bowles e as palavras sem margens de uma ficcionalidade expatriada. E-mail: joaoaugustolira@ hotmail.com
\end{abstract}

\section{Resumo}

Este trabalho propõe destacar nos estudos tradutórios do texto ficcional a singularidade de uma ocorrência onde a tradução assume uma função lapidar como meio configurador da escritura literária.

\begin{abstract}
This work highlights within the translation studies of fictional text the uniqueness of an occurrence in which translation assumes an essential function as means for setting the literary writing.
\end{abstract}

É a cada vez o contexto que, como se diz, decide sobre o sentido assumido pela palavra numa tal circunstância de discurso; a partir daí, as disputas sobre as palavras podem ser sem-fim: o que você quis dizer? É no jogo da questão e da resposta que as coisas se tornam mais precisas ou se embrulham. Pois não há apenas os contextos patentes, há também os contextos escondidos e o que chamamos conotações, as quais nem sempre são intelectuais, mas afetivas, nem sempre são públicas, mas próprias a um meio, uma classe, um grupo, até mesmo um círculo secreto; há, assim, toda uma margem do não dito, percorrida por todas as figuras do escondido.

Paul Ricoeur

\section{Apresentação}

O conjunto da obra literária do escritor marroquino Mohammed Mrabet não existiria sem a mediação tradutória do escritor norte-americano Paul Bowles devido a uma circunstancialidade capital: Mohammed Mrabet é analfabeto. Ele não sabe ler nem escrever em língua alguma. Entretanto, ele possui o talento primordial para a criação da ficcionalidade: ele é um exímio contador de estórias.

Mohammed Mrabet possui uma obra publicada que soma mais de dez títulos, sendo considerado o autor de alguns dos mais belos escritos da literatura árabe moderna. A possibilidade de existência deste evento singular ocorreu graças aos esforços do exercício tradutório empreendido pelo autor norte-americano Paul Bowles, através do qual a tradição da oralidade literária marroquina - originalmente produzida no dialeto Moghrebi - ganhou os contornos da palavra escrita em um código linguístico estrangeiro: a língua inglesa. 
A proposta deste trabalho é trilhar o background da produção desta transposição linguística tomando como referência de fundamentação a interculturalidade dialógica envolvida neste processo, ressaltando a relevância do papel do tradutor.

\section{1) Questões preliminares}

A presente abordagem suscita uma série de questionamentos e interrogações (devido ao caráter singular da natureza discursiva sobre a qual se debruçam os seus esforços analíticos e especulativos), que subjazem às bases, referências, circunstâncias e particularidades das suas motivações, iniciativas, práticas, e subsequente concretização do objeto focalizado: a tradução da oralidade ficcional do storyteller marroquino Mohammed Mrabet (1936-) narrada originalmente no dialeto Magreb e transformada em escritura literária na língua inglesa pelo escritor norte-americano Paul Bowles (1910-1999).

De imediato, um aspecto intrigante se apresenta. Se aquilo a que chamamos de Literatura - a Arte da Palavra - possui as raízes fecundas de sua legitimidade no código da língua que a gera - cuja força motriz de sua história e significância a torna genuína -, como classificar a escrita de uma obra literária e nomear a sua autoria ao serem codificadas e perenizadas em uma língua estrangeira, estranha ao repertório codificador do seu imaginário e das suas origens referenciais circunscritas no advento da oralidade? Não podemos negar que estamos lidando com um intricado jogo especular de dualidades entrecruzadas. Eis o ditame possibilitador de tal ocorrência, o farol de suas múltiplas imagens, o eco de suas vozes várias, e o norteamento de seus enredos multifacetados: as singulares encruzilhadas e as zonas de contato estabelecidas nos trâmites dialógicos dos seus discursos diferenciais.

Assim instalado o questionamento capital e determinante da condição problemática do objeto abordado, deflagram-se interrogações e colocações particularizadas que pretendem vasculhar as suas condições de produção a fim de dar-lhes respaldo, propósito e justificativa. Ao levantar a questão acerca da legitimidade do produto final de sua realização, ou seja, o conjunto da obra de tradição oral de Mohammed Mrabet, traduzida, textualizada, editada e publicada por Paul Bowles, a primeira interrogação que se sobressai aponta para o aspecto da autoria. Como é possível nomear o autor de uma obra literária sendo ele um indivíduo analfabeto que não sabe ler nem escrever? Qual a natureza da pertinência cabal possível de legitimá-lo como criador de uma ficcionalidade textual da qual ele assina a autoria, e mais, que é categorizada como estatuto identitário de uma nacionalidade - uma literatura marroquina -, sendo esta concretizada no código linguístico da língua de outra nacionalidade identitária? Até que ponto o nomeado autor é o produtor genuíno da obra que se escreve sob o seu nome? Até que ponto o papel do autor e do tradutor se delimitam e se entrecruzam?

Assim chegamos ao foco crucial de nossa abordagem, e que permeará as perspectivas que vislumbram o objeto analisado como o lastro essencial sobre o qual a sua ocorrência se 
edifica. Tudo se elabora em função da presença assertiva e participativa do Outro e do empreendimento dual da transubstanciação significante de diferenças que confluem na construção de um discurso tradutório híbrido e multifacetado.

A Outridade se faz regra da mediação de práticas que articulam o dialogismo referencial entre os agentes de sua realização: o autor das fontes originárias e o tradutor instituidor da sua forma escritural.

\section{2) Duas faces de uma mesma moeda}

Mohammed Mrabet e Paul Bowles. Em todas as publicações dos livros de Mohammed Mrabet traduzidos por Paul Bowles, na página de catalogação da obra, o Copyright sempre apresenta a seguinte ordem de registro: Copyright (C) (data) by Mohammed Mrabet and Paul Bowles. Este pequeno detalhe - que não poderíamos deixar passar despercebido pela própria natureza e propósito de nossa abordagem - desperta, na verdade, uma grande curiosidade, e também, a inevitável observância de uma incerteza. Afinal, quem é o autor da obra catalogada? Mrabet ou Bowles? Ou seria mais apropriado falar em os autores em vez de $o$ autor? E assim sendo, a pergunta então mudaria para: Mrabet e Bowles? Mas como assim? Se logo em seguida, na página de rosto do livro encontramos a designação de Mohammed Mrabet como autor e Paul Bowles como tradutor, seguindo-se um breve enunciado explicativo: transcribed and adapted from the tape in Moghrebi (sugerindo, ou melhor, afirmando que tenha sido transcrito e adaptado a partir de gravações em fita cassete no dialeto Magreb). Enunciado este um tanto esclarecedor, pois estabelece a dependência indispensável da intervenção do tradutor para que seja possível a existência da obra que temos em mão, viabilizando o fato de podermos lê-la.

Mohammed Mrabet e Paul Bowles. Dois homens. Duas histórias. Dois mundos. Duas origens. Um encontro de diferenças. Uma singular confluência de encruzilhadas. Um latente interesse em comum: o contato e o diálogo com a Outridade. Diferenças, encruzilhadas e Outridade. Eis os elementos de uma equação especular cujas combinações e matizes interculturais resultaram no advento da experiência tradutória que trouxe à luz através da escrita um patrimônio ficcional impregnado de encantamento, de magia, de perplexidade; e que, paralelamente, promoveram visibilidade e respeito identitário às riquezas culturais das margens periféricas ao hegemônico cânone ocidental.

Mohammed Mrabet e Paul Bowles. O primeiro, um simples pescador profissional marroquino, apaixonado pelo mar, e um profícuo contador de estórias, herdeiro nato da tradição oral dos griots, os contadores de histórias africanos; misto de cronistas e intérpretes da alma coletiva, e também chamados de cantadores, cujas histórias carregam uma forte marca de musicalidade com suas melodias envolventes, aliciantes e hipnotizantes. No prefácio da novela $O$ Limão (1969), a única obra de Mohammed Mrabet publicada no Brasil 
pela editora Nova Fronteira, traduzida do inglês (leia-se: traduzido da tradução originalmente feita por Paul Bowles) por Carlos Lacerda, o tradutor para o português não hesita em declarar sua admiração ou, melhor seria dizer, a sua estupefação ao fazer em forma de prefácio uma apresentação do autor tangerino (tudo que é da cidade marroquina de Tanger é tangerino). Segundo as palavras de Carlos Lacerda (1969, p. III), ao introduzir quem é Mohammed Mrabet logo no início da apresentação: "Cheguei a duvidar da sua existência. Fui ver. Agora que o encontrei não duvido mais. Tenho certeza que ele não existe”. E ao longo do texto que vai delineando a existência quase mágica de tal indivíduo de quem ele havia traduzido uma obra literária, ele conclui:

É ainda uma força da natureza, temperada por séculos de cultura árabe inserida no seu sangue a começar pela arte de contar histórias, de lhes acrescentar, no arrepio da fumaça, uma imagem, um pormenor, um personagem. [...] Ao traduzi-la [referindo-se à novela] procurei ser fiel ao espírito do texto. Trata-se de um autor que reproduz a vida de um menino. Este não conta a história, mas é como se fosse ele próprio a contar. O vocabulário é curto, as repetições, frequentes. O modo de contar é muito importante, tem a qualidade literária da obra espontânea, ou seja, a aparente simplicidade, a construção linear, a volta constante ao mesmo tema, para fixar a atenção do ouvinte-leitor. É isto que a torna inteligível pelo mais ignorante e sedutora para o mais requintado dos leitores. A sua conseguida e tão dificilmente atingível simplicidade vem desse despojamento da história contada, como por uma criança, como para crianças. No entanto, como os seus personagens vivem! (Lacerda, 1969, p.VII-VIII).

Neste trecho da apresentação de Mohammed Mrabet feita por Carlos Lacerda, tradutor brasileiro de uma de suas obras, é possível detectar algumas ideias-chave que nos conduzem a certas circunstâncias subliminares e essenciais empreendidas por Paul Bowles no exercício tradutório de transcrever as suas histórias narradas oralmente a partir de gravações em fitas cassete. Duas passagens da apresentação de Lacerda nos proporcionam tais ideias-chave. A primeira, quando ele fala em ter sido fiel ao espírito do texto e a segunda quando ele observa o papel do autor/narrador que conta a história da personagem, ao afirmar que ele não conta a história, mas é como se fosse ele próprio a contar. Estas duas instâncias nos revelam involuntária, indireta e resumidamente todo um conjunto de intencionalidades e propósitos que justificam a autoridade de Paul Bowles enquanto tradutor das histórias de Mohammed Mrabet.

Em consonância com as ideias de Richard Pattenson expressas em artigo intitulado Paul Bowles/Mohammed Mrabet: Translation, Transformation, and Transcultural Discourse (1992), publicado no The Journal of Narrative Technique, nós encontramos uma explanação dos procedimentos técnicos articulados por Paul Bowles na atividade de traduzir a ficcionalidade narrativa produzida pela oralidade literária de Mohammed Mrabet.

What Bowles does in effect, is to read an oral text, interpret it, then reconstruct it in English, bringing into being a written work that is simultaneously a version of an original and an original work itself. In each case there is a story, authored by the teller, that was recorded on 
a tape, and a piece of literature, written by Bowles, that is the same and yet not the same as the story. While the storyteller's imagination is beyond doubt the conceptual source of the story, the absence of a written text of the storyteller's precise words enhance, to say the least, the authority of the translator. [...] The only way to appreciate these stories for what they are is to accept the duality of their genesis. The oral discourse in Maghrebi and the written discourse in English are each, in their own way, the originals ${ }^{\mathrm{i}}$ (Patteson, 1992, p.182-183, grifos do autor).

Mas afinal, quem foi Paul Bowles? O que subjaz a esta sua autoridade enquanto tradutor/autor da obra de Mohammed Mrabet? Bowles foi um nova-iorquino nascido no distrito de Jamaica, no Queens, estudante da Universidade da Virginia, que aos 21 anos vai para Paris, bebe nas fontes modernas do surrealismo, sofre a influência intrigante - e extremamente valorosa - da também escritora norte-americana Gertrude Stein, tornando-se ainda um requisitado compositor e diretor musical de produções teatrais da Broadway, mas que, antes de tudo era um inquietante outsider, um indivíduo voltado para a busca diferencial das grandes distâncias com as suas múltiplas diferenças e particularidades, e quem encontrou na literatura o terreno propício para a elaboração das encruzilhadas do seu singular discurso artístico, expatriando-se no Marrocos durante mais da metade de sua longa vida.

Paul Bowles foi antes de tudo um viajante. Esta sua intrínseca necessidade de deslocamento parece ter sido a grande força propulsora do seu pensamento e da sua arte. No cerne da variedade deste contínuo deslocar-se, ele construiu todo um universo ficcional. E não adianta querer situá-lo apenas como um autor de literatura de viagens, pois não procede. Mais adequado seria classificá-lo como autor de uma literatura de olhares; olhares errantes, desviados, perturbadores, e muitas vezes extremos; que acabavam por desestabilizar visões solidificadas, buscando contemplar através de suas lentes incisivas a vasta amplitude das verticalidades e horizontalidades do espírito humano e de suas múltiplas vozes.

As experiências de natureza multicultural, transcultural, intercultural refletidas no conjunto da obra ficcional e tradutória de Paul Bowles nos conduzem a estas instâncias. No enredar de suas histórias e traduções, estas vozes estão sempre se expressando, não apenas falando, mas significando ao se fazer presente; por assim estar inserida na cena da presença, ou seja, na cena do jogo dialógico que as fazem falar e, portanto, existir. O fato de empreender esta dialogicidade com o universo da margem e, nela inserido, desenvolver sua produção literária e fazer do seu exercício tradutório o meio configurador da literatura de outros autores - como no caso da tradução e escritura da oralidade ficcional de Mohammed Mrabet -, ele também se faz agente de um ato de resgate e preservação. Ele assume esforços de reconstruir ou preservar a imagem e o patrimônio de culturas, povos, e indivíduos que perderam o referencial de identidade frente às forças seculares e devastadoras do colonialismo imperialista. Paul Bowles se engaja indiretamente nesta missão. A sua entrega é tamanha que ele se transporta para a condição do Outro, do diferente, do excluído, atrevendo-se a 
incorporar as suas vozes e os seus olhares. Ele se desconstrói experimentando colocar-se no lugar do Outro.

My own belief is that the people of the alien cultures are being ravaged not so much by the byproducts of our civilization, as by the irrational longing on the part of members of their own educated minorities to cease being themselves and become Westerners ii (Bowles, 2006, p. XXII).

A atitude de entrega de Bowles é de tal forma incondicional, fazendo com que ele se coloque no lugar do Outro marginalizado para defendê-lo da ameaçadora e sedutora descaracterização cultural que o ronda e que lhe é imposta. Edmund White destaca uma passagem do romance The Spider's House (1955) em que, na voz de uma personagem expatriada, um estrangeiro que há muito possui residência fixa no Marrocos, vê-se refletida uma forte denúncia contra o crescente processo de Ocidentalização do Oriente. Assim fala a voz da personagem, que se confunde com a própria voz do autor Paul Bowles:

When I first came here it was a pure country. There were music and dancing and magic every day in the streets. Now it's finished. Everything. Even the religion. In a few more years the whole country will be like all the other Muslims countries, just a huge European slum, full of poverty and hatred ${ }^{\text {iii }}$ (Bowles apud White, 2006, p. XVI).

Quanto a esta posição, Paul Bowles sempre se manteve inabalável. Ele passa a defender as culturas marginalizadas não apenas do poder opressor dos grandes centros, mas também da ambição das margens de querer se espelhar nos centros de forma anômala, ao se acreditarem também como ocidentais, negando as raízes milenares de sua identidade. Bowles empreende esta defesa através de uma narratividade cheia de tensões e de ataques velados, também utilizando o exercício tradutório como instrumento propulsor de preservação identitária, traduzindo obras de autores na maioria marroquinos como Mohammed Mrabet, Ahmed Yacoubi e Mohamed Choukri.

Na apresentação de seu volume de ensaios Their Heads Are Green and Their Hands Are Blue (1963), encontra-se claramente as bases que sustentam esta sua posição.

Claude Lévi-Strauss, the anthropologist, claims that in order for the Western world to continue to function properly it must constantly get rid of vast quantities of waste matter, which it dumps on less fortunate peoples. What travel discloses to us first of all is our own garbage, flung in the face of humanity ${ }^{\text {iv }}$ (Bowles, 2006, p. XXII).

É preciso ressaltar que na obra de Paul Bowles não existe uma catalogação. Ele não cria tipos, mas sim indivíduos. Daí a intimidade de seu diálogo com as margens. Ele tem a habilidade de adentrar a subjetividade do Outro com segura propriedade, e à medida que ele torna presente a sua voz diferenciada, ele o humaniza. São nestas circunstâncias que os limites especulares entre opostos e diferentes se diluem, como se fundissem uma única moeda 
valorativa. Ele não opera a projeção de uma ideia que se tem do Outro, mas sim uma construção legitimada, independente de qualquer padronização ou rótulos. Nem, tampouco, existe a apropriação total da identidade do Outro, o que implicaria em tomar-lhe o papel de sua totalidade, o que seria completamente impossível, posto que, sempre haverá algo preservado e que não se compartilha na legitimidade das diferenças. O que existe são aproximações, visitações, zonas de contato que conduzem o Outro para além de qualquer condição pré-estabelecida, e para lugares e situações em que ele nunca esteve. Não há pretensão de criá-lo, mas sim construí-lo fazendo o uso participativo de suas vozes e de suas diferentes perspectivas. É dotado deste posicionamento e do jogo entrecruzados destes intentos singulares que Paul Bowles adquire a autoridade tradutória com que consegue legitimar em escritura literária a ficcionalidade oral de Mohammed Mrabet.

\section{3 ) Literatura/Tradução como arma de legitimação e visibilidade identitária}

Da forma como Paul Bowles estabelece um íntimo diálogo com as culturas de margem periférica, estas culturas e seus indivíduos passam pelo olhar ocidental de um homem branco americano, de centro, mas são destilados no filtro do humanismo, do existencialismo, do surrealismo, e da desconstrução; tendências cujas forças sempre se opuseram a qualquer tipo de privação, descaso, desamparo, esquecimento, ou indiferença; tudo isto fruto irrevogável de grandes injustiças. O que Bowles busca empreender, na verdade, é uma desconstrução e reconstrução do Outro, ritmada pela desconstrução e reconstrução de si mesmo. Estas desconstruções urdidas no seio de uma severa desmistificação são os verdadeiros agentes reconstrutores da imagem e da identidade de culturas e indivíduos marginalizados. Na obra de Bowles, eles não são considerados dignos de pena. Eles se confundem com os agentes do seu próprio silêncio e invisibilidade. Eles não são inocentes. Eles não são maquiados com valores de redenção e salvação. Eles não são vitimados. Eles representam o próprio valor de suas originalidades, qualquer que seja a forma como se apresentem. Eles também se perdem. Porém, eles nunca perderão a sua condição primordial de seres humanos, compartilhando do tempo e da história como qualquer pessoa sob o sol.

Mas até que ponto estes empreendimentos discursivos empreendidos pela literatura e traduções produzidas por Paul Bowles agem efetivamente a favor dos propósitos de coletividade que ele defende? Qual o alcance da força de suas palavras? Em que ele inova e contra quais águas ele defere as suas correntes? Muitos estudiosos vêm ao longo da história contemporânea questionando e levantando lutas em defesa de culturas e povos marginalizados, grande parte comunidades pós-colonizadas, que viveram sob um crivo rígido de descaracterização da sua identidade cultural por séculos. As vítimas mais ilustres deste complô histórico são aquelas provenientes do Oriente, englobando África, Ásia, e todo Oriente Médio. E também aqueles da América Latina e do Leste Europeu. Ou seja, parece que 
quase o mundo inteiro é margem. O que não for América do Norte e Europa é margem. Mas, o restante é simplesmente quase tudo. Tamanha ironia histórica.

De uma maneira muito particular, com um olhar intenso e revelador sobre as singularidades da natureza humana, Paul Bowles vem contribuir, e engrossar a legião dos que dedicaram a sua vida lutando pela reconstrução e reconhecimento das identidades das margens oprimidas e pós-colonizadas. Dentre eles não poderíamos deixar de citar Edward Said (1935-2003), representante do grupo dos Orientalistas, autor de obras fundamentais como Orientalismo (1978) e Cultura e Imperialismo (1993), que discutem exaustivamente variados aspectos das relações entre o mundo ocidental centralizado e o oriente marginalizado e hostilizado. Sobre esta tendência de alerta, vigilância, e campanha pela retomada de direitos culturais e humanos perdidos ao longo dos séculos, ele nos dá uma clara definição.

Orientalismo é um estilo de pensamento baseado na distinção ontológica e epistemológica feita entre o Oriente e (na maioria das vezes) o Ocidente. Desta forma, um grande número de escritores, entre eles, poetas, novelistas, filósofos, teóricos políticos, e ativistas preocupados com o Oriente, seus povos, seus costumes, sua forma de pensar, sua alma, seu destino, e tudo o mais. Este Orientalismo, nós podemos encontrá-lo desde Ésquilo, passando por Victor Hugo, Dante, e Karl Marx (Said, 2005, p.12, grifos do autor).

Para Said, existe na ideia irreal e abstrata que o Ocidente cria do Oriente todo um jogo de construção de natureza totalitária, que impõe a nações e culturas inteiras, repletas de variedades e complexidades, um termo de homogeneidade cruel, transformando-os em uma massa uniforme, classificando-os da maneira que melhor lhes convier. Imaginando-os no simulacro de um isolamento conceitual, sem considerar as suas capacidades de variação, de movimentação, de articulação, de originalidade. O seu projeto não propõe uma simples recolocação dos conceitos de Oriente ou Ocidente. Ele propõe o combate, não apenas uma desmistificação, mas um compromisso de igualdade e solidariedade. Seu discurso é revolucionário à medida que clama por uma verdadeira insurreição contra um pensamento de atitudes totalitárias. Ele procura arregimentar gritos sonoros, dispostos a se insurgir contra o massacre ideológico, cultural e humano, submetido ao Oriente, juntamente com todo o entorno periférico e subalterno dos grandes centros da hegemonia capitalista.

As desconstruções articuladas por Paul Bowles operam a favor deste grito de alerta. $\mathrm{Na}$ elaboração de sua obra ele vai desconstruindo sutilmente a ideia e a atitude com que um indivíduo de centro, branco, ocidental, civilizado, se porta frente às culturas da grande margem, ou de qualquer identidade marginal. Ele é em si mesmo o centro que se desloca e se entrega incondicionalmente. Daí o alcance de seu grito velado. A sua entrega incondicional o põe à prova do Outro. Ele estreita a relação de duas singularidades, e não de duas essências incontestáveis nem de duas oposições. Com isso ele se aproxima do projeto de Said, que não acreditava em uma essência do Oriente e outra do Ocidente. A essência é a mesma: o humano. É desta forma que ele vai descosendo um código de padronização do indivíduo colonizado e 
marginal, construído pelo imperialismo colonial, que o destitui de qualquer particularidade individual, relegando-o a um protótipo carnavalizado de exotismo e mistério que denotam ignorância e primitivismo.

Sob o termo deste código, eles não passam de títeres e marionetes desfrutáveis e disponíveis, expoentes fundamentais de uma usura, e consequentemente, de um ressentimento embrutecedor. Sobre o ressentimento mencionado acima, não existe melhor exemplo do que os seguintes versos extraídos do poema Missing Person de Adil Jussawalla, um poeta de Bombaim, citado no livro The Location of Culture (1994), de Homi Bhabha, em um capítulo que ele interroga sobre a construção da identidade. Os versos de Jussawalla são de uma simplicidade implacável.

\author{
One day I learnt \\ a secret art, Invisible-Ness, it was called \\ I think it worked \\ as even now you look \\ But never see me... \\ Only my eyes will remain to watch and to haunt, \\ and to turn your dreams \\ to chaos $^{\mathrm{v}}$ (Jussawalla apud Bhabha, 1994, p. 46).
}

A invisibilidade, esta arte secreta que resta aos indivíduos da margem reflete a indiferença e o descaso que o centro lhes reserva. Eles são invisíveis, mas eles estão lá, sempre úteis quando necessário. Talvez daí venha o seu componente mágico, o seu denotativo exótico. Eles são na verdade uma miragem aos olhos do ocidente. Um fetiche. Uma quimera. Algo que não faz parte de sua compreensão, algo distante, algo diferente. Os centros não costumam estar abertos às diferenças. As suas negociações são mais eficazes e lucrativas com a semelhança. Bhabha define muito bem esta relação falha de reconhecimento.

Esta imagem da identidade humana e, certamente, a identidade humana como imagem ambas molduras ou espelhos familiares do eu [selfhood] que fala das profundezas da cultura ocidental - estão inscritas no signo da semelhança. A relação analógica unifica a experiência de autoconsciência ao encontrar, dentro do espelho da natureza, a certeza simbólica do signo da cultura baseada em uma analogia com a compulsão a crer quando fita um objeto. Isto é parte da obsessão do Ocidente com o fato de que nossa relação primária com os objetos e com nós mesmos é análoga à percepção visual (Bhabha, 1998, p. 84).

O que Homi Bhabha procura salientar é um tipo de praticidade excessiva e unilateral orquestrada pelo mundo ocidental, montado em tudo aquilo que seja claro, óbvio, esperado, definido e finalizado em si mesmo. De preferência, de cores conhecidas, de tonalidades familiares, e com uma troca de interesses bastante semelhantes. Se o processo desta troca é quebrado pela falta de reconhecimento, ou pela falta de interesse por um determinado objeto de visualização, instala-se um descrédito que, de forma natural e oportuna, procura justificar 
uma indiferença; elemento muito propício às investidas manifestas do domínio e da exploração.

Se os indivíduos ocidentais fitam um objeto e não conseguem compreendê-lo, este objeto pode até ser olhado, mas não é visto apropriadamente. Assim feito, ele passa a não existir, ou pelo menos, a não ser visto como algo plausível de reconhecimento. Daí a sua invisibilidade. A visão ocidental age primordialmente no querer ter tudo de valor que brilha aos seus olhos. Ter valor é fundamental para a referência do centro, e para toda a noção do Bem que o sustenta. $\mathrm{O}$ homem ocidental se sente naturalmente tentado a apropriar-se daquilo sobre o que lança o seu olhar de interesse, mesmo não enxergando o que pensa estar vendo.

Esta visão é totalmente desconstruída pela literatura e pela função de tradutor exercida por Paul Bowles. Esta invisibilidade é preenchida com novas cores e novos tons. Os indivíduos e os seus espaços não são apenas vistos, reconhecidos, como também resgatados nos seus valores, na sua beleza, na sua singularidade, no seu silêncio, na sua consciência, na sua subjetividade. A eles não é legado nenhum critério de valorização diferenciada. A eles relega-se e reclama-se apenas o direito soberano de existência, de participação, de identidade, e de memória. E é exatamente com o background constitutivo do urdimento desta discursividade que ele arregimenta - no caso da tradução da obra de Mohammed Mrabet - os instrumentos operadores do processo singular de concretização de uma escritura literária cujas fontes são o repertório do imaginário identitário de uma cultura de margem, fazendo insurgir a luminescência e vigor dos seus dizeres no código linguístico de uma língua de centro.

Corroborando a ideia de que a obra de Paul Bowles trafega por inúmeros territórios diferenciados do fazer literário - devido à multiplicidade de temas e efeitos promovidos pelo seu ofício de escritor e tradutor -, alguns estudiosos e apreciadores do conjunto de suas produções chegam a classificá-las em partes, distribuindo-a em categorias variadas, tanto aplicando esta diversificação aos seus romances e contos, quanto aos seus trabalhos de tradução.

O escritor Gore Vidal (1994), por exemplo, divide a produção dos contos de Paul Bowles em três categorias bastante pertinentes: (a) contos de localidade, em que a paisagem se faz ponto essencial da narrativa; (b) contos de dialogicidade, em que indivíduos pertencentes a culturas estranhas dialogam na confrontação (aproximação e distanciamento) de suas diferenças; e (c) contos da transferência de identidades, em que se imprime uma maior intensidade na aplicação de suas influências surrealistas, quando o mágico e o onírico se fazem regra de suas experimentações.

É neste terceiro grupo que encontramos alguns indicadores mais enfáticos dos procedimentos instrumentalizadores com que ele se utiliza e procede a tradução da obra de Mohammed Mrabet com mais propriedade devido à natureza dos componentes ficcionais que as caracterizam. 
A intensidade destas estórias faz delas algo mais semelhante a delírios do que palavras combinadas no papel. A transferência de identidades se passa de tal modo que nos leva a duvidar e perguntar, afinal, quem é quem, e o que é o quê. $O$ efeito é bastante comparável ao da estória taoísta do homem que sonhou ser uma borboleta. Quando acordou de repente, não sabia se ele era Chuang Chu, o qual havia sonhado ser uma borboleta, ou se era uma borboleta sonhando ser Chuang Chu. Entre Chuang Chu e a borboleta deve haver alguma distinção. Isso é que se chama transformação das coisas (Vidal, 1994, p. 11).

Na rica variedade de temas, espaços, intenções, e efeitos de que é composta a sua literatura, encontramos o incorporar frequente de uma série de particularidades da cultura com a qual Paul Bowles estabelece os seus jogos especulares de transferência, e em especial a cultura marroquina.

O elemento chave que ele escolhe para configurar o tom e os efeitos da condução destas narrativas é a interferência alucinógena do kif - um tipo de erva alucinógena análoga aos efeitos da cannabis -, que é um elemento bastante relevante na cultura do povo marroquino, tendo o mesmo peso cultural de elementos como a música, a dança, o folclore, e os mitos do seu imaginário.

Moroccan kif-smokers like to speak of two worlds, the one ruled by inexorable natural laws, and the other, the kif world, in which each person perceives reality according to the projections of his own essence, the state of consciousness in which the elements of the physical universe are automatically rearranged by cannabis to suit the requirements of the individual. These distorted variations in themselves generally are of scant interest to anyone but the subject at the time he is experiencing them. An intelligent smoker, nevertheless, can aid in directing the process of deformation in such a way that the results will have value to him in his daily life. If he has faith in the accuracy of his interpretations, he will accept them as decisive, and use them to determine a subsequent plan of action. Thus, for a dedicated smoker, the passage to the other world is often a pilgrimage undertaken for the express purpose of oracular consultation ${ }^{\mathrm{vi}}$ (Bowles, 1986, p. 9, grifos do autor).

É nesta perspectiva oracular - de definir a realidade como um resultado das projeções da própria essência individual - que Paul Bowles insere a presença do kif na criação de sua produção literária e tradutória. Bowles foi participante de uma geração cujo uso dos alucinógenos era o mais legítimo passaporte para ir além dos limites da percepção. A utilização destes alucinógenos no exercício experimental de adentrar as profundezas do inconsciente foi um hábito comum a muitos escritores como Allen Ginsberg, William S. Burroughs, Gregory Corso, Jack Kerouac, e tantos outros. Artistas de forte influência surrealista, dadaísta, e beatnik, que experimentaram exaustivamente dar vazão ao fluxo genuíno da linguagem, sem a interferência e a imposição dos limites da consciência. Estas experiências revolucionárias trouxeram profundas contribuições e incalculáveis mudanças ao universo da criação literária. E Mohammed Mrabet sempre foi um assíduo fumante do kif, sendo a maioria das histórias contadas por ele quando ele estava sob o seu efeito oracular, e na maioria das vezes, ele narrava as histórias enquanto fumava. 
As mais expansivas viagens ao mundo do inconsciente trouxeram para a literatura a licença de negociação com a liberdade sem limites que rege o plano do onírico. Para estes artistas não se devia procurar significado em lugares e circunstâncias óbvias, mas sim deixar que estes significados pudessem emergir como insights das conexões que o real travasse com o imaginário no plano do inconsciente, e fazer destes insights as pontes reveladoras que conduzem o indivíduo ao cerne de mistérios invioláveis e o fazem compartilhar com perplexidade o sentido inaudito de suas forças.

Trilhando os caminhos destas transferências de identidades, nós entramos no terreno das mais férteis e mágicas encruzilhadas construídas pela literatura e pelas traduções realizadas por Paul Bowles.

\section{Conclusão}

No diálogo multifacetado que se estabelece estas transferências de identidades, Paul Bowles dilata um diapasão de incalculáveis identidades, e faz com que as suas vozes anunciem o tributo peculiar das originalidades de cada uma.

Não apenas ao sabor do tempo germinal que a tudo desgasta e das suas intempéries erosivas que a tudo derruba, mas também ao sabor da jovialidade erotizante de suas vicissitudes, e no ardor da presença substancial com que elas se impõem ao tempo, e tentam lapidar na beleza ofuscante, no amor desesperado, e na esperança ilusória, o quinhão de magia e maravilha que este sonho absurdo e cruel o qual chamamos de existência ainda consegue nos ofertar.

Os elementos que configuram o conjunto composicional das categorias de sua ficcionalidade - localidade, dialogicidade e transferência de identidades - esquematizam as encruzilhadas da sistemática com que ele ousa, experimenta, e tem autoridade legitimada para transcrever e traduzir em sua própria língua, ou seja, fazendo-se ele mesmo o instrumento da possibilidade de tal transposição, proporcionando ao mundo das letras e do saber a sabedoria, o encantamento e a magia da rica tradição oral do universo ficcional de Mohammed Mrabet, como se não quisesse deixar escapar tamanho patrimônio cultural e identitário fadado a perder-se na imensidão dos ventos do esquecimento.

A instrumentalização da experiência literária e tradutória de Paul Bowles utiliza o confronto e a incapacidade de comunicação entre diferentes culturas como se tocasse um instrumento musical cujas cordas são nervuras latentes da natureza humana, como um verdadeiro maestro da sugestão e da apreensão.

Ele nos desafia, nos surpreende, e nos enriquece com a potencialidade inovadora e reprodutiva de suas palavras na perspectiva, no drama, e nas particularidades que representam. Ele só nos acrescenta com o manipular das peças do jogo performático de seu discurso literário, seja ele fruto de sua própria imaginação ou da imaginação de outro. 
As imagens, sugestões, vertigens, e intentos que Bowles faz despertar ao assumir o olhar, o lugar, o tempo, o papel, a voz, e a palavra do Outro em seus escritos, mostra que ele vai muito além da simples experimentação de diferentes pontos de vista.

As frutíferas encruzilhadas criadas pelo traçado da narratividade expatriada de Paul Bowles são construídas no ordenamento estilístico de uma gramática ficcional e tradutória dotada de critérios próprios em que as confrontações e metamorfoses entre o Eu e o Outro, o real e o imaginário, o palpável e o onírico, o plausível e o absurdo, o silêncio e o deserto, são peças chaves na elaboração das suas tramas, de seus efeitos, e do seu verbo.

\footnotetext{
${ }^{\mathrm{i}} \mathrm{O}$ que Bowles faz na verdade é ler um texto oral, interpretá-lo e, em seguida, reconstruí-lo em inglês, ao criar um trabalho escrito que é, simultaneamente, uma versão de um original e uma própria obra original. Em cada caso, há uma história, de autoria do contador, que foi gravado em uma fita, e uma peça de literatura, escrita por Bowles, que é a mesma, ainda que não seja o mesmo da história. Enquanto a imaginação do contador é sem sombra de dúvida a origem conceitual da história, a ausência de um texto escrito com palavras precisas por parte do seu contador capacita - para dizer o mínimo - a autoridade do tradutor. [...] A única maneira de apreciar estas histórias pelo o que elas são é aceitar a dualidade de sua gênese. $O$ discurso oral no dialeto Magreb e o discurso escrito em inglês são cada um, à sua maneira, originais (tradução nossa, grifos do autor).
}

${ }^{i i}$ Minha crença pessoal é que pessoas de culturas alienígenas estão sendo destruídas nem tanto pelos subprodutos de nossa civilização, mas sim pelo desejo irracional por parte dos próprios membros letrados de suas minorias em deixar de ser aquilo o que são para transformarem-se em Ocidentais (tradução nossa).

iii Quando eu vim aqui pela primeira vez, este era um país puro. Havia música, dança, e magia todo dia nas ruas. Agora, isto tudo acabou. Até mesmo a religião. Daqui a poucos anos, todo o país será como os outros países mulçumanos, uma imensa favela europeia, cheia de miséria e rancor (tradução nossa).

${ }^{\text {iv }}$ Claude Lévi-Strauss, o antropólogo, afirma que, para continuar a funcionar convenientemente, o mundo Ocidental precisa constantemente livrar-se de vastas quantidades de matéria residual, que é despejada sobre povos menos afortunados. O que o ato de viajar nos revela antes de tudo é o nosso próprio lixo, jogado na cara da humanidade (tradução nossa).

${ }^{v}$ Um dia eu aprendi/ uma arte secreta, Invisibilidade, ela era chamada/ Eu penso que ela funcionou/ como agora mesmo você olha/ Mas nunca me vê.../ Apenas meus olhos continuarão a observar e a assombrar, / e tornar seus sonhos um caos (tradução nossa).

${ }^{\text {vi }}$ Os marroquinos fumantes do kif gostam de falar em dois mundos, um que é regido pelas inexoráveis leis naturais, e outro, o mundo do kif, no qual cada pessoa percebe a realidade de acordo com as projeções de sua própria essência, o estado de consciência no qual os elementos do universo físico são automaticamente reestruturados pela cannabis para se adequar aos requisitos do individual. Estas variações distorcidas são geralmente de pouco interesse para alguém além do momento em que o sujeito está a experimentá-las. Um fumante inteligente, entretanto, pode auxiliar no direcionamento deste processo de deformação, de uma forma que os resultados sejam úteis na sua vida cotidiana. Se ele tem fé na verdade de suas interpretações, ele irá aceitá-las como decisivas, e usá-las para determinar um subsequente plano de ação. Desta forma, para um fumante dedicado, a passagem para este outro mundo é frequentemente uma peregrinação empreendida com o expresso propósito de uma consulta oracular (tradução nossa, grifos do autor).

\section{Referências bibliográficas}

BHABHA, Homi. The location of culture. 2. ed. London and New York: Routledge, 1994. 
O local da cultura. Trad. Myriam Ávila. Belo Horizonte: UFMG Editora, 1998.

BOWLES, Paul. A hundred camels in the courtyard. San Francisco: City Lights, 1986.

Perennial, 2006.

Their heads are green and their hands are blue. New York: Harper

LACERDA, Carlos. “Apresentação de Mohammed Mrabet”. In: MRABET, M. O limão. Trad. Carlos Lacerda. Rio de Janeiro: Editora Nova Fronteira, 1969, pp. III-XI.

PATTESON, Richard. "Paul Bowles/Mohammed Mrabet: translation, transformation, and transcultural discourse". The Journal of Narrative Technique. Michigan, v. 22, n. 3, pp.180-190, Fall, 1992.

SAID, Edward. Trabalho intelectual e crítica social. 3. ed. São Paulo: Casa Amarela, 2005.

VIDAL, Gore. "Introdução". In: BOWLES, Paul. Chá nas montanhas. Trad. Rubens Figueiredo. Rio de Janeiro: Rocco, 1994, pp. 07-12.

WHITE, Edmund. "The high price of solitude". In: BOWLES, Paul. Their heads are green and their hands are blue. New York: Harper Perennial, 2006, pp. xii-xix. 